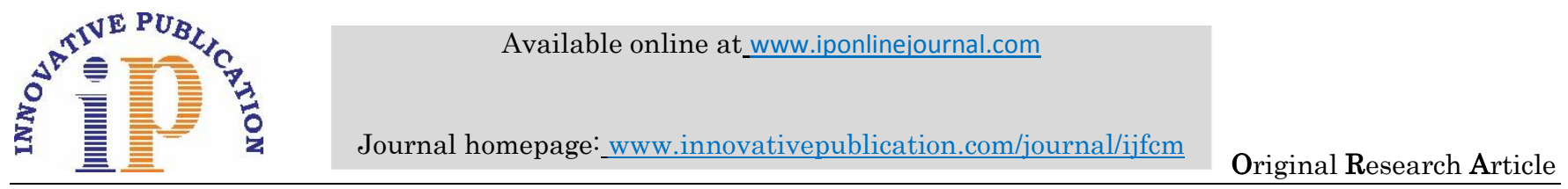

\title{
An autopsy review of 78 cases of suicide by hanging in benin
}

\section{Cedric E. Bigot ${ }^{1 *}$, Jean Marie Adovoekpe ${ }^{2}$, Falilatou Seidou ${ }^{3}$, Luc Brun $^{4}$, Fabien Houngbe ${ }^{5}$}

${ }^{4,5}$ Professor, ${ }^{1,3,5}$ Faculte des Science de la Sante (University d' Abomey-Calavi), Benin, ${ }^{2,4}$ Faculte de Medecine (University de Parakou), Benin

\begin{abstract}
Introduction: Hanging is one of the most common methods of suicide. It can also be used to conceal a crime. Thus, it is important to systematically have a forensic autopsy performed in cases of hanging. Only that examination can determine the actual forensic form of the death. At the national level, there is no epidemiological data on suicide by hanging in Benin.

Aims: This study aims to describe the epidemiological and forensic features observed in the cases of suicide by hanging in Benin.

Material and Methods: This is a descriptive and retrospective study of all the suicidal deaths by hanging collated in the Forensic \& Legal Medicine Unit of the Faculty of Health Sciences (UML_FSS) for a period of 12 years, 2005-2017, in Benin.

Result: Suicides by hanging accounted for $8.3 \%$ of the cases of suspicious deaths autopsied in the south and center of Benin. Males represented $85.9 \%$ of the corpses, and most individuals were under 40 years old $(62.0 \%)$. Hangings were complete in $65.4 \%$ of the cases. The material used most often for hanging (28.7\% of cases) was nylon rope. Subcutaneous hemorrhages (46.2\%) and ecchymosis in the sterno-cleido-mastoid muscles $(61.3 \%)$ were the most common finding at the neck dissection.

Conclusion: Hanging is a common method of suicide, especially among young men. In Benin, it occurs behind closed doors and by means of tools used in everyday life. Forensic autopsies, however, remain infrequent in cases of suicides.
\end{abstract}

Keywords: Hanging, Suicide, Autopsy, Benin.

\section{Introduction}

Suicide is one of the leading causes of violent death across the world and is a significant public health problem. ${ }^{1}$ According to estimates disclosed by the World Health Organization (WHO), more than 800,000 people die annually by killing themselves. Globally, the suicide rate is estimated at 10.67 cases per population of 100,000 people. According to that source, South and East Asia, Africa, and Europe are the three regions most affected by suicides. Suicide rates in those three regions were 13.3, 12.8, and 11.9 cases, respectively, per 100,000 inhabitants in $2015 .^{2}$ In Benin, the suicide rate was estimated at 15 cases per 100,000 people. $^{3}$ As elsewhere, suicide affects more men than women and its causes are multifactorial.

Hanging is one of the most common methods of suicide. It accounts for $5-12 \%$ of the cases investigated in forensic and legal medicine., ${ }^{4,5}$ In Germany and Japan, hanging represents the leading method of suicide. In India, it ranks second. All cases of hanging are not suicide cases. Hanging actually may result from an accident, and it can also be used to conceal a crime. Thus, it is important to systematically perform a forensic autopsy in a case of hanging. Only that examination can determine the actual manner of the death.

Autopsies are conducted infrequently in Benin. They are performed even less in the context of corpses found hanged by the neck. Police officers tend to systematically classify hanging as a suicide, and they do not bother to seek forensic and legal investigations. In most cases, dead bodies are buried without conducting any forensic and legal examination. Therefore, there is no national epidemiological data on suicide by hanging.

The aim of this work is to study the peculiarity and forensic features of the cases of suicide by hanging observed in the south and center of Benin.

\section{Materials and Methods}

This is a descriptive and retrospective study of all the suicidal deaths by hanging collated in the Forensic \& Legal Medicine Unit of the Faculty of Health Sciences (UML_FSS) for a period of 12 years, 2005-2017, in Benin. We included all hanging deaths autopsied during this period, even corpses who were autopsied outside of our facility. The UML_FSS activity covers southern Benin, including eight districts with 6 million people.

The data were collected from the forensic autopsy cases (judicial requisitions and autopsy reports). They accounted for information related to the incident (places of hanging, situation of complete or incomplete hanging), the deceased's profile (age, sex, occupation, and civil status), the type of ligature, the material used, and forensic examination data. The data thus collected were entered and processed using the software SPSS. The qualitative variables were presented as proportions with their frequencies. A bi-variate analysis using chi $^{2}$ or Fisher's tests was used to compare qualitative variables according to the circumstances in which they should apply. The test is significant if $\mathrm{p}$ is less than 0.05 .

The study has been authorised by the Ethics Committee of the Faculty of Health Sciences/University of Abomey-

*Corresponding Author: Cedric E. Bigot, Faculte des Science de la Sante (University d' Abomey-Calavi), Benin

Email: bigot.ce@gmail.com

http://doi.org/10.18231/J.IJFCM.2019.028 
Calavi. It complied with anonymity of the deceased and confidentiality of judicial proceedings.

\section{Results}

\section{Frequency of hangings}

During the time span of the study, 937 cases of suspicious death were processed by the forensic unit. Suicide by hanging was designated as the manner of death in 78 cases.

Figure 1 describes the distribution of suspicious deaths and suicides by hanging over time.

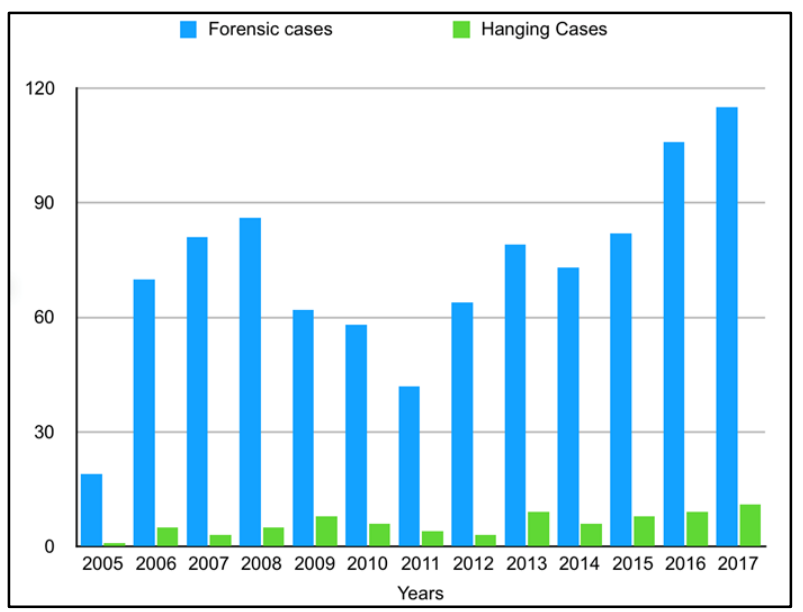

Fig. 1: Forensics and hanging cases distribution from 2015 to 2017

\section{Profile of suicidal subjects}

Among the 78 cases of suicide by hanging, 67 were males $(85.9 \%)$, and the sex ratio was $6: 1$. The mean age of the deceased was $36+/-6$ years. Most corpses were those of individuals under 40 years old $(62.0 \%)$. Single individuals $(n=42)$ and craftsmen $(n=34)$ were the predominant groups. Table 1 describes the distribution of cases according to social characteristics, including the sex and age of the deceased.

\section{Characteristics of hanging}

Information related to the site of corpse discovery could not be specified for 43 cases. These cases of hanging were all recorded before 2013. Most corpses were found in confined and enclosed spaces $(n=25), 32.1 \%$ of cases. Those confined spaces were dwelling houses $(n=13)$, detention centers $(\mathrm{n}=3)$, or detached / derelict buildings $(\mathrm{n}=9)$. In 9 cases, the corpses were discovered in an open space, including 2 in public places.

Hangings were complete $(n=51)$ in $65.4 \%$ of cases and incomplete $(n=27)$ in $34.6 \%$ of cases. Different tools were used for hanging. The ropes used for hanging were, by frequency in ascending order: waist belt $(\mathrm{n}=1)$, rubber rope $(n=3)$, rope made with garment or piece of cloth $(n=7)$, and nylon strings. $(n=31)$.

\section{Ligature marks}

Among the 78 corpses, $20.5 \% \quad(n=16)$ presented an incomplete ligature mark with a posterior knot. In the other cases, the knot was left lateral $(44.9 \%)$ or right lateral (33.3\%). The ligature mark was mostly in the form of $\mathrm{U}$ $(n=66)$ in $84.6 \%$ of cases and infrequently located under the hyoid bone ( 8 cases). Abrasions were associated with the ligature marks in $64.1 \%$ of cases.

\section{Neck dissection}

Level-by-level dissection of the neck has highlighted:

1. Subcutaneous hemorrhages $(n=37)$ in $47.4 \%$ of cases;

2. Ecchymosis in the sterno-cleido-mastoid (SCM) muscles $(n=48)$ in $61.5 \%$ of cases;

3. Hyoid bone fracture $(n=8)$ in $10.3 \%$ of cases;

4. Injuries of thyroid cartilage $(n=3)$ in $3.8 \%$ of cases;

5. Fracture / luxation of the cervical spine $(n=1)$ in $1.3 \%$ of cases.

Table 2 describes the distribution of injuries in the different neck structures according to the type of hanging.

Table 1: Distribution of cases according to social characteristics of the deceased

\begin{tabular}{|c|c|c|}
\hline Characteristics & n & \% \\
\hline Sex & 67 & 85.9 \\
\hline Male & 11 & 14.1 \\
\hline Female & & \\
\hline Age group (years) & 4 & 5.1 \\
\hline$<20$ & 31 & 39.7 \\
\hline $20-29$ & 15 & 19.2 \\
\hline $30-30$ & 9 & 11.5 \\
\hline $40-49$ & 4 & 5.1 \\
\hline $50-59$ & 3 & 3.8 \\
\hline$>59$ & 12 & 15.4 \\
\hline Unspecified & & 53.8 \\
\hline Marital status & 42 & 26.9 \\
\hline Single & 21 & 2.6 \\
\hline Married & 2 & 16.7 \\
\hline Widow & 13 & \\
\hline Unspecified & & \\
\hline
\end{tabular}




\begin{tabular}{|c|c|c|}
\hline Professional situation & & \\
\hline Student & 7 & 9.0 \\
\hline Apprentice & 9 & 11.5 \\
\hline Craftman & 34 & 43.6 \\
\hline Farmer & 5 & 6.4 \\
\hline employee & 6 & 7.7 \\
\hline Unspecified & 17 & 21.8 \\
\hline
\end{tabular}

Table 2: Distribution of injuries in the different neck structures according to type of hanging

\begin{tabular}{|l|c|c|c|c|}
\hline & \multicolumn{2}{|c|}{ Complete hanging } & \multicolumn{2}{c|}{ Incomplete hanging } \\
\hline \multicolumn{1}{|c|}{ Neck Injuries } & $\mathrm{n}=51$ & $(\%)$ & $\mathrm{n}=27$ & $(\%)$ \\
\hline subcutaneous hemorrhages & 26 & $(51.0)$ & 11 & $(40.7)$ \\
\hline ecchymosis in the SCM muscles & 35 & $(68.6)$ & 13 & $(48.1)$ \\
\hline Fracture of hyoide bone & 7 & $(13.7)$ & 1 & $(3.7)$ \\
\hline injuries of thyroid cartilage & 3 & $(5.9)$ & - & \\
\hline fracture / luxation of the cervical spine & 1 & $(2.0)$ & - & \\
\hline
\end{tabular}

\section{Discussion}

This study reports the cases of hanging examined by the Forensic \& Legal Medicine Unit of Cotonou. The data cover all the administrative regions located in the south and center of the country. They are far from being complete. Nevertheless, the data reflect the different aspects of cases of suicide by hanging observed in Benin.

Our research work indicates that suicides by hanging accounted for $8.3 \%$ of cases of suspicious deaths autopsied in Benin. The unit records, on average, $6+/-3$ cases per year. Besides, several cases of hanging were not managed by the Forensic \& Legal Medicine Unit, either because the parents of the deceased buried the latter without informing the judicial authority or because, after being informed, the judicial authority did not consider it necessary to open an investigation or granted the family's request to have the corpse buried without autopsy. It remains true that the frequency of suicides by hanging in that part of Benin is very low compared to the frequencies observed in countries such as South Africa, ${ }^{6}$ Egypt,${ }^{7}$ Turkey, ${ }^{8}$ Canada, ${ }^{9}$ and Saudi Arabia. $^{10}$

In our series, suicide by hanging mainly involves men and young people. It does not spare any occupational category, and it affects both single people and those living as couples. There are significant differences between the suicide cases identified in our cohort and the several series described in Asia, ${ }^{11,12}$ and Europe. ${ }^{13,4}$ One contrast is the circumstances of corpse discovery. In our cohort, we observe a significant proportion of people who choose to hang themselves away from their residence. In a study conducted in Egypt, Rao observed that $91.7 \%$ of suicides occurred at home. ${ }^{7}$ That difference may be due to houses in Benin being highly overcrowded. To avoid a rescue, the suicidal subject will choose a remote and isolated area for hanging. Several suicidal subjects also chose to hang themselves far from their ordinary place of residence, justifying the $14.1 \%$ of the corpses that could have not been identified.

The description of furrow left on the neck by the bond used for hanging is crucial in hanging cases. Furrow position, its form, and nearby injuries are useful in clarifying the cases. In our cohort, most furrows are in the form of $U$ and pass over or at the level of the hyoid cartilage. This observation is consistent with the findings of other studies. ${ }^{7,14}$ These studies report that the hanging knot is more often on the sides than on the posterior face of the neck. A study conducted in India from 2013 to 2017 highlighted a relative association between knot position and its nature. According to the authors of this study, the hanging noose would be more often posterior, whereas the fixed knot was generally located on the lateral sides of the neck. ${ }^{15}$ In the context of Benin, forensic medical examiners have few opportunities to thoroughly consider the hanging bond since it is cut before or after corpse removal.

The material used in most hanging cases in our series was nylon rope. This material is easily accessible and commonly used in everyday life, especially to collect water. The nature of the material used for hanging is specific to each sociocultural context. ${ }^{16}$ In Asia, and particularly India, nylon rope and sari are most often encountered, ${ }^{14}$ whereas in Europe there are ropes of synthetic materials, waist belts, electric cables, and pet leashes. ${ }^{17}$

Regarding thanatological aspects, we observed that subcutaneous hemorrhages, desquamations, and ecchymosis of neck muscles were the most common vital organ injuries. The presence of these injuries suggests that compression of the cervical cord is antemortem. There is a strong relationship between these injuries and the material used. ${ }^{16}$

Fracture of the hyoid bone and injuries of laryngeal cartilages are described as being rare and even exceptional events in cases of hanging. A recent literature review ${ }^{18}$ indicates that the frequency of that type of injury varies widely, from 0 to $83 \%$. According to the explanations offered by the review authors, this variability in frequency depends on diagnostic methods used. They consider that direct observation and palpation of the larynx do not always help make a diagnosis of fracture of the hyoid bone or laryngeal cartilages. In the series in which postmortem scanning was performed before forensic autopsy, or among 
those in which stereomicroscopy was used, the frequency of hyoid bone injuries and laryngeal cartilages rose $70 \%$. According to research conducted by Mukhopadhyay, ${ }^{19}$ fractures of the hyoid bone are influenced by anatomical features, including the length of horns and width of bone body. The second factor is the type of hanging. Injuries of the hyoid bone and cartilages are more common in cases of complete hanging. ${ }^{20}$

\section{Conclusion}

Hanging is a common method of suicide, especially among young men. In Benin, it occurs behind closed doors and by means of tools used in everyday life. Forensic autopsies, however, remain infrequent in cases of suicides.

\section{Source of Funding}

None.

\section{Conflict of Interest}

None.

\section{References}

1. WHO. Mental health action plan 2013-2020. World Health Organization; 2013 [cited 2018 May 1]. Available from: http://apps.who.int/iris/handle/10665/89966

2. WHO. GHO Suicide rates, age-standardized - Data by WHO region. WHO. 2016 [cited 2018 May 1]. Available from: http://apps.who.int/gho/data/view.main.MHSUICIDEASDRR EGv?lang=fr

3. WHO. GHO Suicide rates, age-standardized - Data by country. WHO. 2016 [cited 2018 May 1]. Available from: http://apps.who.int/gho/data/view.main.MHSUICIDEASDRv?1 ang $=\mathrm{fr}$

4. Facy F. Suicide in France. Soins. 2017;62(814):18-22.

5. Gunnell D, Bennewith O, Hawton K, Simkin S, Kapur N. The epidemiology and prevention of suicide by hanging: a systematic review. Int J Epidemiol 2005;34(2):433-42.

6. Meel B. A study on the incidence of suicide by hanging in the sub-region of Transkei, South Africa. J Clin Forensic Med 2003;10(3):153-7.

7. Rao D. An autopsy study of death due to Suicidal Hanging 264 cases. Egypt J Forensic Sci 2016;6(3):248-54.

8. Taktak S, Kumral B, Unsal A, Ozdes T, Buyuk Y, Celik S et al. Suicidal hanging in Istanbul, Turkey: 1979-2012 Autopsy results. J Forensic Leg Med 2015;33:44-9.
9. Tugaleva E, Gorassini DR, Shkrum MJ. Retrospective Analysis of Hanging Deaths in Ontario. J Forensic Sci 2016;61(6):1498-507.

10. Al Madni OM, Kharoshah MAA, Zaki MK, Ghaleb SS. Hanging deaths in Dammam, Kingdom of Saudi Arabia. $J$ Forensic Leg Med 2010;17(5):265-8.

11. Ma J, Jing H, Zeng Y, Tao L, Yang Y, Ma K, et al. Retrospective analysis of 319 hanging and strangulation cases between 2001 and 2014 in Shanghai. J Forensic Leg Med 2016;42:19-24.

12. Atreya A, Kanchan T. Clinico-epidemiological study of nearhanging cases - An investigation from Nepal. J Forensic Leg Med 2015;33:35-8.

13. Naudó-Molist J, Arrufat Nebot FX, Sala Matavera I, Milà Villaroel R, Briones-Buixassa L, Jiménez Nuño J et al. A descriptive analysis of suicide deaths and application of the Psychological Autopsy method during the period 2013-2015 in the region of Osona (Barcelona, Spain). Rev Esp Med Leg 2017;43(4):138-45.

14. Sharma BR, Harish D, Sharma A, Sharma S, Singh H. Injuries to neck structures in deaths due to constriction of neck, with a special reference to hanging. J Forensic Leg Med 2008;15(5):298-305.

15. Mishra PK, Tomar J, Varun A, Verna Pankaj. Profile of deaths due to hanging- An autopsy based retrospective study at a tertiary care centre in Indore. Indian J Forensic Community Med 2018;5(1):34-8.

16. Ambade VN, Tumram N, Meshram S, Borkar J. Ligature material in hanging deaths: The neglected area in forensic examination. Egypt J Forensic Sci 2015;5(3):109-13.

17. Gunnell D, Bennewith O, Hawton K, Simkin S, Kapur N. The epidemiology and prevention of suicide by hanging: a systematic review. Int J Epidemiol 2005;34(2):433-42.

18. Khokhlov VD. Trauma to the hyoid bone and laryngeal cartilages in hanging: Review of forensic research series since 1856. Leg Med 2015;17(1):17-23.

19. Mukhopadhyay PP. Predictors of hyoid fracture in hanging: Discriminant function analysis of morphometric variables. Leg Med 2010;12(3):113-6.

20. Khokhlov VD. Calculation of tension exerted on a ligature in incomplete hanging. Forensic Sci Int 2001;123(2-3):172-7.

How to cite this article: Bigot $\mathrm{C}$, Adovoekpe JM, Seidou F, Brun L, Houngbe F. An autopsy review of 78 cases of suicide by hanging in benin. Indian J Forensic Community Med 2019;6(3):121-4. 